\title{
Publisher
}

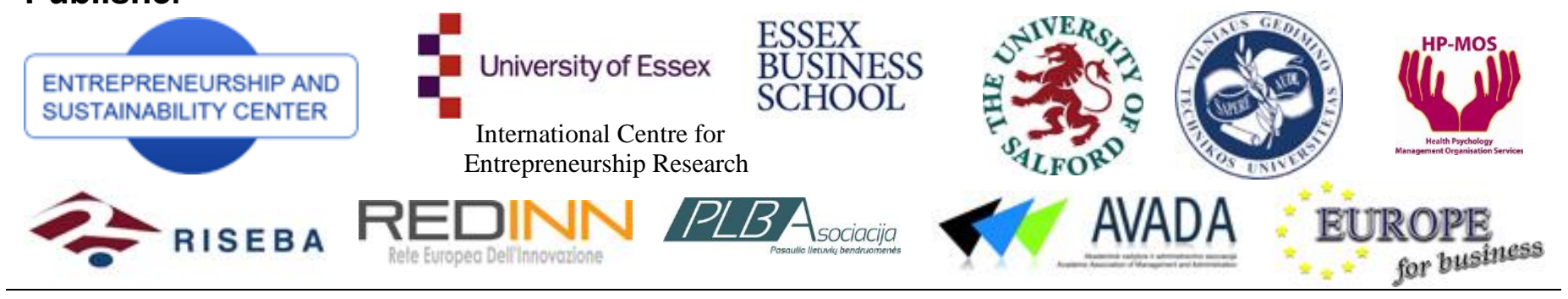

\author{
The International Journal \\ ENTREPRENEURSHIP AND SUSTAINABILITY ISSUES \\ ISSN 2345-0282 (online) http://jssidoi.org/jesi/aims-and-scope-of-research/ \\ 2016 Volume 3 Number 3 (March)
}

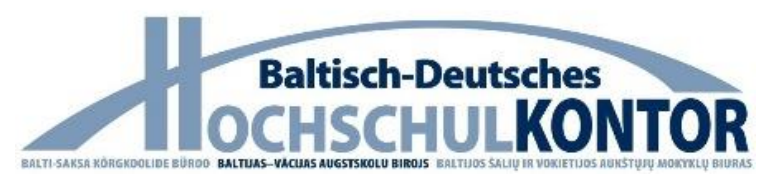

„The paper was published with support from the Baltic-German University Liaison Office from funds of the German Academic Exchange Service (DAAD)"

\section{E-Residency: A BUSINESS PLATFORM FOR INDUSTRY 4.0?}

\author{
Gunnar Prause \\ Tallinn University of Technology \\ School of Economics and Business Administration \\ Akadeemia Tee 3, 12618 Tallinn, Estonia \\ E-mail: gunnar.prause@ttu.ee
}

\begin{abstract}
E-government is a popular topic on the political agenda and many countries are working on the development and improvement of e-services. But e-government is more than the provision of public services electronically - it also means the implementation of consequent process-oriented procedures supporting management and organisational structures within public and private institutions. Until now the customers' needs, especially the requirements of entrepreneurs and small and medium-sized enterprises (SME) in the context of international supply chains have not been in the focus of most e-governmental service developments. This may change with the spread of Industry 4.0 which aims for the fusion of the virtual and the physical world paving the way to smart production and logistics solutions touching the entire supply chain from product design and development, operations management and logistics to distribution. But Industry 4.0 also requires new business models and structures together with new concepts for managing information and business administration. A first big step towards the implementation of such Industry 4.0-oriented business concept is embodied by the Estonian development of "e-Residency", which might be an appropriate e-business approach for Industry 4.0 and which takes into account the perspective of internationally operating entrepreneurs and SME's. Currently, companies start to gain first experience with concepts like production in networks or smart logistics and they begin to develop new organisational structures and models to benefit more from the opportunities that the new technology offers. The paper addresses the research question of how the e-residency concept might facilitate the development and implementation of Industry 4.0 and how entrepreneurs and SMEs may benefit more from new Industry 4.0-related business models by using the e-residency platform of Estonia.
\end{abstract}

Keywords: e-Residency, Industry 4.0, e-Services, SME, Supply Chains

Reference to this paper should be made as follows: Prause, G. 2016. E-Residency: a business platform for Industry 4.0?, Entrepreneurship and Sustainability Issues 3(3): 216-227.

DOI: http://dx.doi.org/10.9770/jesi.2016.3.3(1) 
JEL Classifications: L14, M21.

\section{Introduction}

Government seems to be a major factor influencing the development of SMEs development (Smallbone and Welter, 2001). Consequently, European Union and most countries explicitly consider e-government as an instrument for cutting red tape. But e-government is more than the provision of public services in an electronic form - it also means the implementation of consequent process-oriented procedures, i.e. the design of egovernmental solutions should cope with the organisational structures of business and public administration and it should also map the organisational perspective into technical substructures (Reidolf and Prause, 2012). It is, therefore, important to understand the needs of the target groups of e-government services in order to create suitable e-service solutions. But studies show that there are already big differences in the e-governmental landscape in the countries around the Baltic Sea as well as in the needs of small and large companies (Lille and Prause, 2009).

This challenge also appears during the design of e-services for smart production and logistics, especially under the frame condition of internationally operating entrepreneurs and SMEs. Recently the whole production field is characterised by increased interest since after long time of decline, manufacturing and re-industrialization enjoy a renaissance on the Western economic agenda because politicians, business leaders and scientists recall the role of the industrial sector as a key driver of research, productivity, and job creation. Industry generates $80 \%$ of the EU's private innovations and $75 \%$ of its exports. Despite these facts a view into the statistical figures reveals that the global share of European manufacturing value added dropped from 36\% in 1991 to 25\% in 2012 (Veugelers, 2013; Heymann and Vetter, 2013; Dudzevičiūtè, 2013; Tvaronavičienè, 2014; Grubicka, Matuska, 2015).

Many manufacturing initiatives have been started in different parts of the world and a very promising approach seems to be the fusion of the virtual and the real world, i.e. the linkage between internet and manufacturing aiming to develop cyber-physical systems (CPS) and dynamic production networks in order to achieve flexible and open value chains in manufacturing of complex mass customization products in small series up to lot size 1 (Ramsauer, 2013). The German approach has been called "Industry 4.0" and aims also for energy and resource efficiency, increased productivity, shortening of innovation and time-to-market cycles together with a horizontal and vertical integration through value networks and an end-to-end digital integration of engineering across the entire value chain. Internet-linked production facilities and networked manufacturing systems open up a machine-to-machine-communication and interaction (Kagermann et al., 2013; Gerlitz, 2015). The successful realisation of Industry 4.0 requires $R \& D$ activities and progress in eight key areas comprising standardisation and open standards for a reference architecture, the management of complex systems, the delivering of a comprehensive broadband infrastructure for industry, safety and security issues, work organisation and work design in digital industrial age, specific training and continuing professional development, an appropriate regularity framework as well as resource efficiency. But the R\&D needs for Industry 4.0 go far beyond sophisticated production expertise, what is also required is especially ICT related knowledge covering cyber security, e-commerce and e-government (Prause, 2015a; Štitilis, Klišauskas 2015.).

By scanning the European arena of e-services it turns out that the Republic of Estonia represents one of the leading e-governmental countries in Europe and it is the first country worldwide which offers a transnational digital identity called "e-Residency" (e-Estonia, 2015). "e-Residency" is a sophisticated form of e-business allowing an entrepreneur or SME employee to administer a location-independent business online, i.e. "eResidency" and offers the opportunity to run a trusted company online. As Prause (2015b) pointed out the concept of e-residency is in line with ongoing approaches in the context of Industry 4.0 trying to realise the fusion of the virtual and the real world, i.e. the linkage between internet and manufacturing leading to concepts of smart supply chain management. Until now, only little research has been carried out on the requirements of e- 
governmental services in the context of Industry 4.0. The literature review of existing e-governmental solutions focusing on Industry 4.0 especially for entrepreneurs and SME indicates a research gap in this specific field. For this reason, the paper addresses the research questions of how e-services for Industry 4.0 might look like and why the concepts of Industry 4.0 and e-residency might be complementary by taking into account the needs of internationally operating entrepreneurs and SMEs. The paper is subdivided into the following parts. First part provides the theoretical background for Industry 4.0 together with related e-governmental services with an emphasis on the needs of the SME sector. Afterwards, the research methodology for the empirical part is described. Subsequently, the empirical results of the conducted expert interviews, case studies and workshops are presented and discussed. Finally, the paper finishes with conclusions and implications.

\section{Theoretical background}

In order to spur manufacturing, re-industrialisation and industrial competitiveness in Western countries new concepts for smart production and logistics have been started. A promising approach seems to be the fusion of the virtual and the real world, i.e., the linkage between internet and manufacturing. In Germany, the most important industrial EU country, this approach has been called "Industry 4.0". Industry 4.0 aims to develop cyber-physical systems and dynamic production networks in order to achieve flexible and open value chains in the manufacturing of complex mass customisation products in a small series up to lot size 1.

But Industry 4.0 has even higher ambitions, targeting energy and resource efficiency, the shortening of innovation and time-to-market cycles, as well as a rise in productivity. In this sense, Industry 4.0 represents nothing less than the fourth industrial revolution, comprising 3D printing, big data, Internet of Things and Internet of Services, i.e., all of the ingredients needed to facilitate smart manufacturing and logistics processes. Thus, Industry 4.0 shall bring the competitiveness in the manufacturing and high-tech sectors back to Western countries with particularly promising perspectives for the BSR due to their high innovation level, sophisticated ICT infrastructure, and highly qualified workforce (Kagermann et al., 2013). Industry 4.0 leads to new supply chain paradigms based on complex and intertwined manufacturing networks with changed roles of designers, physical product suppliers, clients and logistics service providers making it possible to identify and to trace single products during their entire life-cycle and even more because in industry 4.0 it becomes possible for products to organise and choose their own way through the production and related logistics processes (Bauer et al., 2014).

The fusion of cyber space and material world in Industry 4.0 leads to virtual structures in the value and supply chains, which require organisational and managerial tasks for related cross-company operations processes in networks touching manufacturing, logistics and distribution (Sydow and Möllering, 2009). These management tasks are realised and controlled by information flows within the Industry 4.0 networks and they are running parallel to the physical value and supply chain flow (Jacobs and Chase, 2014). Consequently, the physical value streams in Industry 4.0-related supply chains require an appropriate cyber-platform to be able to control the parallel information streams and to handle the related business administration tasks.

When it comes to the online administration of location-independent business the Republic of Estonia represents one leading actor in Europe offering to anyone who is interested in a transnational digital identity such internetbased business solutions. A very sophisticated form of e-business which Estonia offers as the first country worldwide is called "e-Residency" which comprises a government-issued digital identity enabling the user to run a trusted company online. One important target of Estonian e-residency is to unleash the world's entrepreneurial potential but the e-residency concept is also compatible with ongoing approaches in the context of Industry 4.0 since it realises the fusion of the virtual and the real world in the context of smart supply chain management. It emphasizes and recognizes, furthermore, the needs of the SME sector which are crucial for the success of the Industry 4.0 approach since European manufacturing backbone is dominated by SMEs which combine highly developed ICT skills with high flexibility and innovation (Prause, 2015b). But offering only e-service solutions for SMEs are not sufficient to capitalize the opportunities and efficiencies of Industry 4.0, also new business 
models and structures are required (Prause, 2015b). Since Industry 4.0 aims to create a horizontal integration, the new Industry 4.0-related value chains will be take place in complex and intertwined manufacturing networks, where the underlying supply chains can be characterized by a high degree of fragmentation (Dujin et al., 2014). This fragmentation leads to lower entry barriers for SMEs as well as to new R\&D strategies in multinational value chains between advanced and emerging countries and these developments spur again creation of new business models (Belussi and Sedita, 2010).

The organisational aspects of this fragmentation were discussed by Olaniyi and Reidolf (2015) who showed the compatibility of fractal structures with Industry 4.0 by highlighting self-similarity, self-organization, selfoptimization, goal-orientation, and dynamics as wining attributes of flexible and adaptable manufacturing organizations. The fractal approach also embraces intrapreneurship aspects, decentral and lean structures, dynamic and adaptable organisations and cooperation as well as the importance of high performing ICT systems for the linkage of the fractal units (Warnecke 1996). But the limitation on structural aspects for Industry 4.0 is too narrow to deploy the full potential of Industry 4.0; also new business models are necessary (Kagermann et al., 2013; Prause 2015b). Already control of information streams for cross-company value chains in the networks of cyber physical systems of Industry 4.0 require e-services for related business administrational processes which must be imbedded in a coherent way into the Industry 4.0 structures. When developing these e-services it must be kept in mind that especially for small firms the costs for implementation and updating of hard- and software and the transaction costs are often so important that benefits do not matter (Eierle, 2008). There exists also the threat of a digital divide between large and small firms (Lockett and Brown, 2006). A special problem field for small firms emerges when the legislation is changing quickly or is so complex that special experts like tax advisers or consultants should be hired and the costs are raising remarkably (Smallbone and Welter, 2001). ICT can help to reduce transaction and administrative costs and enhance productivity and efficiency of technologies. So policies should encourage SMEs to use ICT as studies show that ICT users are more likely to innovate (Higon, 2011). Research results show that those companies that make greater use of the Internet for their business processes are indeed those that have greater and sustained growth (Amoros et al, 2007).

\section{Methodology}

Until now, little research has been carried out on the requirements of business administration processes in the context of Industry 4.0 and corresponding e-services. For this reason, the paper addresses the research questions of how e-services for Industry 4.0 might look like and why the concepts of Industry 4.0 and e-residency might be complementary by taking into account the needs of internationally operating entrepreneurs and SMEs.

The results of the paper are based on a mix of empirical methods for data collection and data analysis and the underlying research design can be described as flexible according to Robson (1993) since the research uses mainly a qualitative approach. The present qualitative research uses desk research, in-depth interviews with entrepreneurs and e-government experts, which were conducted during two European projects. The first project was carried out within the FP7 programme between 2013 and 2016 and is called "Crossing Boundaries" aiming for the exploration of the processes, challenges and implications on innovation performance of knowledge and technology transfer across national boundaries (CB, 2016). The second project is called "EgoPrise" and it ran in the frame of the BSR Interreg programme between 2010 and 2012 with the aim to make public authority services more receptive to the needs of businesses, especially for the benefits of small and medium-sized enterprises in rural areas of the Baltic Sea region (Prause et al., 2012). Whereas the focus of the "Crossing Boundaries" project was more on transnational innovation processes, the main objective of the "EgoPrise" project was to understand the requirements and needs of e-government services from the perspective of entrepreneurs and SME from the countries around the Baltic Sea.

The qualitative research in the framework of this article included narrative research which comprises for both projects of expert interviews with SMEs, representatives of public administration on state or regional and local 
level, entrepreneurs, and with entrepreneurship umbrella organizations in Estonia, Finland, Germany, Latvia, Lithuania and Sweden. The collected information has been restored and transformed into country-based narrative chronologies and finally summarized into a Baltic Sea collaborative narrative (Creswell 2003; Clandinin and Connelly, 2004).The final data analysis was made using thematic content analysis of the narrative following Anderson (2007). The expert interviews were completed on the bases of case studies mainly in Estonia. Since all the business sectors were represented the in EgoPrise project also the context of Industry 4.0 was investigated. The paper explores in depth through the case study the organisational and administrational structures and business processes of an Estonian high-tech company and the impact and potential of Estonian ICT and e-service infrastructure for the company's success. Complementary, a quantitative survey was conducted in the frame of the EgoPrise project between 2010 and 2013. The questionnaire consisted of closed and open questions which covered, besides the topics of access to e-government services and the assessment of efforts to follow information obligations, concrete questions concerning missing e-services and suggested improvements of existing e-government services from the perspective of SMEs. All together around 400 SMEs from different BSR countries with a focus on Estonian, German, Lithuanian and Swedish enterprises were randomly sampled from the entire population of SMEs and SME managers or entrepreneurs answered the questions in telephone interviews.

\section{Business Administration for Industry 4.0}

The fusion of cyber-world and material world in Industry 4.0 induces virtual structures in the value and supply chains which require organisational and managerial tasks for related cross-company operations processes in networks to control the related information and material flows (Sydow and Möllering, 2009; Jacobs and Chase, 2014). Consequently, the physical value streams in Industry 4.0-related supply chains require an appropriate cyber-platform to be able to control the parallel information streams and to handle the related business administration tasks. Compatible e-services have to fulfil the corresponding business administration tasks and they have to be developed and created according to the user needs.

An empiric survey was launched in the Baltic Sea region in the framework of the EgoPrise project and gave an inside view about the demands and needs concerning e-services for internationally operating entrepreneurs and SMEs (Prause et al., 2012). Firstly, the survey results confirmed the observation made by Lille and Prause (2011) that the needs and expectations towards e-services depend also on the company size and the business sector. Secondly, they revealed that there exists a huge difference among the countries investigated concerning the governmental online-ability. Furthermore, the results of the study showed that even in highly developed egovernment countries the offered e-services are scattered between varieties of different web-sites so that they are not integrated and they do not reflect the business processes and needs of companies. Finally, an important point was related to safety issues since SMEs can be only encouraged to use new ICT services when trusted third parties are able to confirm the safety and usefulness of the system, which emphasises results from Lockett and Brown (2006). Especially internationally operating SMEs and entrepreneurs pointed out the need for standardized, secure, integrated and culturally independent e-services in order to facilitate transnational operations. Consequently, these results confirm the findings of Beckinsale et al (2011) who pointed out, based on studies of ethnic minorities, that to fight digital divide and to facilitate transnational and intercultural entrepreneurial activities standardized processes between countries would help enormously to support operations and to decrease administrative burdens.

By taking into account these considerations, the Estonian Government spurred investigation to improve and internationalise their in European context already highly developed e-governmental system. Recently, the Estonian ministry of Economic Affairs and Communication initiated a study for analysing the sore points for entrepreneurs and SME's participating in international supply and value chains (e-Estonia, 2015). The results of these investigations brought to light that the crucial business administration tasks for internationally operating 
SMEs and entrepreneurs are related to incorporation and administration of legal entities, contracting with clients, suppliers and other companies, access to banks and payments, invoicing as well as exchange with legal and public authorities including taxation (e-Estonia, 2015). These business administration tasks are exactly those which are necessary to control the information streams which are related to material value added streams of transnational supply chains in the context of Industry 4.0 (Figure 1; e-Estonia 2015).

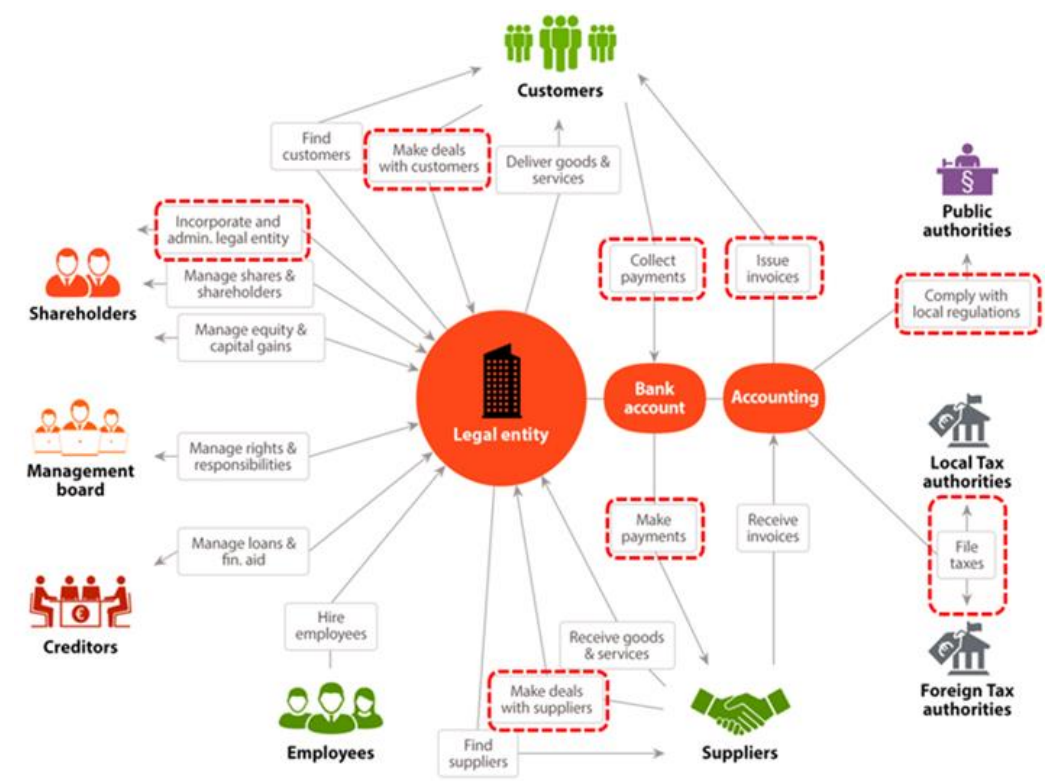

Figure1. Crucial business administration tasks of supply chains for entrepreneurs Source: e-Estonia (2015)

An additional aspect of the survey of the Estonian ministry of Economic Affairs and Communication is depicted in figure 1 highlighting that all stakeholders of a company and its full supply chain are considered in the business administration approach comprising of customers, employees, shareholders, creditors, suppliers, company management and public authorities.

In this sense a transnational business administration platform for Industry 4.0 should consist of a concept that represents the fusion of the cyber and business administration world and which possess the potential to spur the evolvement of further international business models in the context of Industry 4.0, especially for internationally operating entrepreneurs and SME's. In accordance with these reflexions the Estonian e-residency offers a transnational digital identity to internationally operating SMEs and entrepreneurs which is equipped with a portfolio of integrated, standardised, secure and multi-lingual (Estonian, English and Russian) e-services.

The attributed digital services of e-residency are enabling a secure and convenient way to sign and verify the authenticity of digitally signed documents and contracts, to encrypt and transmit documents securely, to establish an Estonian company online and to administer the company from anywhere in the world. Linked to e-residency is the possibility to conduct e-banking and remote money transfers, which represent the payment opportunity of European banking and access to Single European Payment Area (SEPA) system as well as to EU legal space including the advantage of quick and cheap financial transactions inside EU, contracting and enforcing in a reliable Estonian law system as well as the possibility of a remote foundation of an Estonian holding company. Additionally, the e-resident is able to participate in the highly developed Estonian e-government system comprising the declaration of Estonian taxes online as well as all other efficient and easy-to-use e-services (eEstonia, 2015). 
But Kaspar Korjus (2015) continues that e-residency services will not only be limited to services offered by the Estonian state so that e-residency gets an international and non-public dimension: "On the contrary, it is our wish and expectation that the private sector will start to develop new services. We can create great conditions for it". In the meantime private players like LHV, Stripe and PayPal enter the game. An important question in academic literature is how to encourage entrepreneurs to use e-government services. Usually dissemination and learning process should be started with promotional campaigns and success stories to build experience of using egovernment services and to improve social characteristics and knowledge of the end users in order to widen the number of users (Warkentin et al, 2002; Mahadeo 2009). In the case of Estonian e-residency program the development was different since director Kaspar Korjus (2015) states that "What we aim to do is to create a worldwide virtual business environment, where people from both the developed and developing countries can easily become entrepreneurs and start doing business anywhere in the world. Physical national borders and restrictions will no longer present an obstacle. You can start a business, open bank accounts, make transactions, sign contracts and even declare taxes, all on your computer". And it seems that there is a huge demand for those e-services from entrepreneurial side because Korjus (2015) continues that "When we went live with the eestonia.com/e-residents page some months ago, we received over 4,000 applications in 24 hours from people who wished to be kept informed about the e-residency launch. Those contacts came from 140 different countries".

Considering this the approach of the e-residency can be considered to be a fusion of the cyber and business administration world, which might play the role of international business administration platform for Industry 4.0 and possess the potential to spur the evolvement of further international business models in the context of Industry 4.0, especially for internationally operating entrepreneurs and SME's. The "remote" option of eresidents enables entrepreneurs everywhere in the world to use via Estonia a platform for transnational business operations. As a long term advantage entrepreneurs are able to receive an EU-residency after having bought real estate in Estonia. The special advantages for the Estonian side are to develop Estonia via the e-residency to an international business hub with growing service offers for foreign entrepreneurs and investors in the fields of finance, consultancy, accountancy and law services (Prause, 2015c).

\section{An Estonian case study}

How e-services may contribute to internationally operating SME shall be demonstrated by a case study which is dedicated to a very successful Estonian production company Meritex OÜ (the authors changed the company name for publication). The company produces maritime functional wear and has its management headquarters in a rural area in Western Estonia whereas it operates on highly developed foreign markets like Germany, Sweden and UK. In this sense the case study also highlights the impact of the specific Estonian ICT infrastructure together with its cyber system for rural development as well as how the Estonian e-residency concept spurs the evolution of successful international operations of this SME. Meritex has been a research object in "Crossing Boundaries" project where it was studied how the company became a European market leader in functional maritime wear and how strongly the company's success was linked to innovation and to well-developed internet access of large parts of the Estonian rural areas (Olaniyi and Reidolf 2015; Prause 2015b). A sophisticated internal company ICT together with well-developed Estonian ICT infrastructure facilitates the high innovation performance, which is necessary to keep the market leader position of Meritex and which stresses again the observations of Higon (2011).

Meritex OÜ started in 1993 and is currently employing a staff of more than one hundred people in four production locations in Estonia. The business operations are distributed all over the world comprising global sourcing of smart materials from China, USA, Sweden, South Korea and Taiwan, R\&D activities in Germany and Estonia, cutting and production of components in Estonia, sewing in Estonia and Ukraine, and the final assembly in Estonia. Nearly all sales activities are located outside Estonia. The fragmentation of the value and 
supply chains which are characteristic for Industry 4.0 can be observed also in the case of Meritex touching the purchasing and sourcing processes, R\&D activities, integration of "remote" expertise via telework places as well as the manufacturing value chain of the company. The production processes between the company locations in Estonia and Ukraine are interrelated and synchronised by an integrated company-wide goal system and standardized trans-location processes, which are fixed and illustrated by multi-media process documentation including e-learning tools. These activities are related to sewing work which is done in Narva (Estonia) and Ukraine. The core competence and related technologies however are guarded and kept in the Estonian locations comprising the main warehouse, ICT, as well as other complicated and technical processes like cutting, prototypes and high-end products. For example all the parts are cut in Estonia, shipped to Ukraine and other places for sewing and then shipped back to Estonia for final assembling. Even by taking into account the costs for outsourcing to Ukraine including logistics it turned out that these costs are only half as high when compared to a complete production in Estonia. But the well-developed Estonian ICT and internet infrastructure played also a crucial role for the company's success within Estonia and the synchronization of the work in the different Estonian company facilities which are also linked via cyber services.

The Estonian e-governmental services make it possible to run the company operations from the countryside and to manage nearly all business-government tasks related to taxation issues, permits and other applications online in a very efficient 24/7 mode. Beyond that the e-services of e-Estonia are additionally facilitating and visualizing internal company processes like travel statements, holiday declarations, overtime accounting, settlement and exchange of contracts as well as payments since all these organizational tasks can be handled, signed and exchanged electronically between employees and company administration. Consequently, big parts of internal business administration tasks including human resource management issues, financial topics and contracting can be organised online. By using these e-services the company was able to mitigate the lack of high-qualified workforce in the rural areas by integrating needed know-how of Estonian experts and specialists into the Meritex organisation via telework and remote work places in the cities of Tallinn and Tartu. In parallel, the company deployed over the years intensive training and educational activities at their locations which generated a large number of highly-qualified and sustainable workplaces in their rural areas over the last 20 years.

Meanwhile Meritex developed its markets and exports all over Europe with high market shares in Denmark, Finland, France, Germany, UK and Sweden as well as in Australia, whereas the main competitors from other EU countries export only up to five countries. The success story is closely linked to concepts combining smart production and supply chain management on the bases of the smart Estonian cyber and e-service infrastructure which is available even in rural areas. This cyber infrastructure enables Meritex to run distributed multi-national operations and to implement business administration concepts for online management including the marketing activities of European sales which was organised via sales agents representing their national markets. By doing so Meritex demonstrated that even in rural areas high-tech entrepreneurship can be successfully implemented and rural shortcomings like brain drain, elderly population, lack of highly qualified work-force and deficits in mobility can be mitigated. The presented success story of Meritex was based until now largely on the fruitful symbiosis of technology, smart production, innovation and supporting e-services for related business administration processes. Unfortunately these e-services were restricted till 2015 to Estonian citizens and the related business operations were restricted to Europe. With the introduction of e-residency for all citizens of the world this success story has the chance to get globalized.

\section{Implications and Discussions}

Already the original e-governmental services of Estonia besides the digital identity enjoyed a lot of features which followed the recommendations of Beckinsale et al (2011) including integration, standardisation and multilingual e-services in Estonian, English and Russian language enabling entrepreneurs and SMEs the online administering of location-independent business. The restriction to Estonia and Europe has been removed with 
the introduction of the e-residency concept which opened up from 2015 the opportunities of the service portfolio of e-Estonia to all global citizens.

In the case of Meritex the availability of e-residency for partners and suppliers outside Europe has the possibility to facilitate the full global Meritex supply chain and accelerate the business operations beyond European Union. The related efficiency gains can be capitalized in contracting, purchasing, marketing, financial management via SEPA procedures between European banks as well as in the settlement of legal issues between business partners of Meritex by using Estonia as a business and legal platform. E-residency allows to handle and to manage all these tasks fully online under the precondition that the business partners of Meritex apply for Estonian eresidency and they open EU bank accounts. By doing so all business partners who are involved in the international Meritex supply chain are enabled to run via e-residency all related business administration tasks online including the Meritex sales representatives in Australia as well as all its suppliers in Asia, China and the USA, i.e. the use of e-residency services touches the full supply chain from marketing to contracting, payment, logistics up to delivery for low costs.

Additionally, e-residency enables the Meritex partners to handle online efficiently and quickly all governmental tasks related to Estonia. Further advantages are related to intra- and extra-company online processes in personnel management, financial transactions and exchange of information and material flows. This also applies to teleworkers inside and outside Estonia under the precondition of being an e-resident since all documents can be signed, transmitted and handled fully electronically so that the Meritex supply chain-related information and business administration tasks can be treated virtually, i.e. e-residency integrates and brings efficiency and business benefits to all stakeholders in the value chain. But the apparent fragmentation of the value and supply chains require more workflow-oriented solutions which integrate cross-company use of the e-residency services which are just starting to evolve. Here more R\&D activities would be preferable.

In this sense e-residency might be considered as a concept for the management of information streams and business administration issues within supply chains in the context of Industry 4.0, focussing on the needs of internationally operating entrepreneurs and SME's and joining cyber - physical aspects in business administration (Prause, 2015a). Nevertheless this represents only a starting point for the final "Business Administration 4.0" concept since a recent survey from BITKOM et al. (2013) about the "prospects for Industry 4.0" revealed that standardisation, new business models, a regulatory framework and new concepts for process and work organisation were mentioned among the most important challenges of Industry 4.0, i.e. the Estonian first steps have to be continued within Europe as well as in other parts of the world because smart production and logistics together with their international supply chains is a global business (Kargermann et al. 2013).

As Dujin et al. (2014) pointed out Estonia enjoys already now a favourable position concerning Industry 4.0 readiness among the EU15 countries which is significantly strengthened after the launch of e-residency since it facilitates related business administration processes. But by following Prause (2015b) it can be stated that the opportunities of e-residency concept are also supporting new business models in the context of Industry 4.0 which are more geared towards individual, last-minute customer requirements, providing new solutions for dynamic pricing by taking into account the customers' and competitors' situations and by embracing openness and more networking and cooperation aspects between partners in the supply chain compared to now.

\section{Conclusions}

The Estonian e-residency concept represents a first step towards the fusion of the cyber and business administration world taking into account all stakeholders of a company and its full supply chain. The concept is open for international business models in the context of Industry 4.0 and due to its focus on internationally operating entrepreneurs and SME's it enables online business via Estonia. Special features of e-residency are access to the EU-banking system (SEPA) including the advantage of quick and cheap financial transactions 
inside EU, contracting and enforcement in a reliable Estonian law system as well as the possibility of a remote foundation of an Estonian holding company including the favourable Estonian taxation system. Industry 4.0 aims to create a horizontal integration through value networks embracing open, cooperative and secure business models integrating all stakeholders of international supply chains, comprising of customers, employees, shareholders, creditors, suppliers, company management and public authorities, without neglecting the needs of entrepreneurs and SME.

The case study of an Estonian SME with intensive international business operations revealed the potential and the impact of the Estonian portfolio of e-services and pointed out that e-residency might play the role of international business administration platform for Industry 4.0. The case study together with the further discussions highlighted additional efficiency gains by using e-residency for non-European stakeholders in the international company supply chain. In this sense e-residency possesses important characteristics of a transnational business administration platform for Industry 4.0 extending the concept of fusion of the cyber and physical world to business administration processes. The case study also pointed out that this extension bears the potential to spur the evolvement of new business models in the context of Industry 4.0.

By summing up the Estonian e-residency offers a transnational digital identity to internationally operating SMEs and entrepreneurs which is equipped with a portfolio of integrated, standardised, secure and multi lingual eservices which enable the online administering of location-independent business. E-residency facilitates international business operations in the context of Industry 4.0 for entrepreneurs and SMEs and offers a portfolio of e-services which might play the role of suitable platform for the business administration processes of Industry 4.0. Further research is required to specify new e-services according to the needs of Industry 4.0

\section{References}

Amoros JE, Planellas M and Batista-Foguet JM (2007) Does Internet Technology Improve Performance in Small and Medium Enterprises? Evidence from Selected Mexican Firms. Akademia. Revista Latinoamericana de Administracion, 039: 71-91.

Anderson R (2007) Thematic content analysis (TCA): descriptive presentation of qualitative data. Available from Internet: http://www.wellknowingconsulting.org/publications/pdfs/The-maticContent $\neg$ Analysis.pdf.

Bauer, W.; Schlund, S.; Marrenbach, D.; Ganschar, O. (2014). Industry 4.0 - Volkswirtschaftliches Potenzial für Deutschland, BITKOM, Berlin.

Beckinsale M, Ram M and Theodorakopoulos N (2011) ICT adoption and e-business development: Understanding ICT adoption amongst ethnic minority businesses. International Small Business Journal, 29: 193-219

BITKOM; VDMA; ZVEI (2013). Survey “prospects for Industrie 4.0”, Frankfurt.

CB (2016). http://www.crossingboundaries.eu/, access: 28.01 .2016

Clandinin, D. J.; Connelly, F. M. (2004). Narrative Inquiry: Experience and Story in Qualitative Research. $1^{\text {st }}$ edition, Jossey-Bass.

Creswell, J. W. (2003). Research Design: Qualitative, Quantitative, and Mixed Methods Approaches. SAGE Publications.

DOI: http://dx.doi.org/10.9770/jssi.2015.5.1(4)

Dudzevičiūtè, G. (2013). Lithuanian manufacturing trends in the context of developed and developing countries, Entrepreneurship and Sustainability Issues 1(1): 55-66http://dx.doi.org/10.9770/jesi.2013.1.1(6)

Dujin, A.; Geissler, C.; Horstkötter, D. (2014). INDUSTRY 4.0: The new industrial revolution, Roland Berger Strategy Consultants, Munich. 
e-Estonia (2015). https://www.e-estonia.com .

Eierle B (2008) Filing Practice of Small and Medium-sized Companies: Empirical Findings from Austria. International Small Business Journal 26: 491-528.

Gerlitz, L. 2015. Design for product and service innovation in industry 4.0 in emerging smart society, Journal of Security and Sustainability Issues 5(2): 181-198. DOI: http://dx.doi.org/10.9770/jssi.2015.5.2(5)

Grubicka, J.; Matuska, E. (2015). Sustainable entrepreneurship in conditions of UN (Safety) and technological convergence, Entrepreneurship and Sustainability Issues 2(4):188-197. DOI: http://dx.doi.org/10.9770/jesi.2015.2.4(2)

Heymann, E.; Vetter, S. (2013). Europe's re-industrialisation, DB Research, Frankfurt

Higon, D.A. (2011) The impact of ICT on innovation activities: Evidence for UK SMEs. International Small Business Journal, March 14, 20110266242610374484 [Accessed 14 October 2011].

Jacobs, R.; Chase, R. (2014). Operations and Supply Chain Management, 14th edition, McGraw Hill, 762p.

Kagermann, H.; Wahlster, W.; Helbig, J. (2013). Recommendations for implementing the strategic initiative INDUSTRY 4.0, National Academy of Science and Engineering, Berlin/Frankfurt.

Korjus, K. (2015). Estonia's e-residency goes global, Estonian World from 14. May 2015, Tallinn

Lille, M.; Prause, G. (2009). E-Governmental Services in the Baltic Sea Region. Wismar: Wismar University

Locket N and Brown DH (2006) Aggregation and the Role of trusted Third Parties on SME E-Business Engagement. A Regional Policy Issue. International Small Business Journal 24: 379-404.

Mahadeo JD (2009) Towards an Understanding of the Factors Influencing the Acceptance and Diffusion of e-Government Services. Electronic Journal of e-Government [e-journal] 7(4), Available through: Routledge database.

Olaniyi E. O; Reidolf, M (2015). Organisational Innovation Strategies in the Context of Smart Specialization. Journal of Security and Sustainability Issues, 5 (2), 213-227, 10.9770/jssi.2015.5.2(7).

Prause, G. (2015a). Industry 4.0: New Perspectives for Smart Production and Logistics in the Baltic Sea Region, Baltic Rim Economies, 2015(4), p. 41.

Prause, G. (2015b). Sustainable business models and structures for industry 4.0. Journal of Security and Sustainability Issues, 5 (2), 159-169, 10.9770/jssi.2015.5.2(3).

Prause, G.; Hunke, K.; Thessel, F. (2012). Transnational Aspects of End-user Oriented E-services in the Baltic Sea Region. Berlin: Berliner Wissenschafts-Verlag.

Ramsauer, C. (2013). Industry 4.0 - Die Produktion der Zukunft, WINGbusiness 3/2013, 6 - 12.

Reidolf, M.; Prause, G. (2012). EGOPRISE Project: Results and Outlooks. In: Prause, G.; Hunke, K.; Thessel, F. (Ed.). Transnational Aspects of End-user Oriented E-services in the Baltic Sea Region (172-183). Berlin: Berliner Wissenschafts-Verlag.

Robson, C. (1993). Real-world research: A resource for social scientists and practitioner - researchers. Malden: Blackwell Publishing.

Shatrevich, V.; Strautmane, V. (2015). Industrialisation factors in post-industrial society, Entrepreneurship and Sustainability Issues 3(2): 157-172. DOI: http://dx.doi.org/10.9770/jesi.2015.3.2(4)

Smallbone, D.; Welter, F. (2001). The Role of Government in SME Development in Transition Economies. International Small Business Journal, 19(4): 63-77.

Štitilis, D.; Klišauskas, V. (2015) .Journal of Security and Sustainability Issues 5(1):45-57. 
Sydow, J.; Möllering, G. (2009): Produktion in Netzwerken: Make, Buy \& Cooperate. 2. Aufl. Vahlen. München.

Tvaronavičienė, M. (2014). If industrial sector development is sustainable: Lithuania compared to the EU, Entrepreneurship and Sustainability Issues 1(3):134-142. DOI: http://dx.doi.org/10.9770/jesi.2014.1.3(2)

Veugelers, R. (2013). Manufacturing Europe's future, BRUEGEL BLUEPRINT SERIES Volume XXI, Brussels, ISBN: 978-90-7891032-9.

Warkentin, M.; Gefen, D.; Pavlou, P.A.; Rose, G.M. (2002). Encouraging Citizen Adoption of e-Government by Building Trust. Electronic Markets [e-journal] 12(3), Available through: In-formaworld database.

Warnecke, H. (1996). The Fractal Company: A Revolution in Corporate Culture, English Version in 1997, Springer, Berlin.

Gunnar PRAUSE is Professor for International Business in Tallinn School of Economics and Business Administration (TSEBA) of Tallinn University of Technology. Research interests: International Business, Entrepreneurship \& SME - Management, Logistics, Innovation. He is Board Member of the Centre for Business Research and Development at the Department of Business Administration of TSEBA, Board Member of the Institute of Cooperative Studies at Humboldt University Berlin, Board Member of Baltic China Science Park Network. He is author of more than 100 scientific articles.

This is an open access journal and all published articles are licensed under a Creative Commons Attribution 4.0 International License

Copyright of Journal "Entrepreneurship and Sustainability Issues" (c) Entrepreneurship and Sustainability Center, All Rights Reserved 